Metals and Ceramics Division

CRADA FINAL REPORT FOR CRADA NO. ORNL98-0529

\title{
DEVELOPMENT OF ADVANCED CORROSION-RESISTANT Fe-Cr-Ni AUSTENITIC STAINLESS STEEL ALLOY WITH IMPROVED HIGH TEMPERATURE STRENGTH AND CREEP-RESISTANCE
}

\section{P.J. Maziasz and R.W. Swindeman, Oak Ridge National Laboratory}

G.D. Smith, Special Metals Corporation-Huntington Alloys* *(formerly INCO Alloys International, Inc.)

\author{
Prepared by \\ Oak Ridge National Laboratory \\ Oak Ridge, TN 37831 \\ Managed by \\ UT-Battelle, LLC \\ For the \\ U.S. Department of Energy \\ Under contract DE-AC05-00OR22725 \\ Approved for Public Release \\ Unlimited Distribution
}

Research was supported through a CRADA with Special Metals Corporation, sponsored by the U.S. Department of Energy, Office of Fossil Energy, under contract DE-AC05-00OR22725 with Oak Ridge National Laboratory, managed by UT-Battelle, LLC. 


\title{
DEVELOPMENT OF ADVANCED CORROSION-RESISTANT Fe-Cr-Ni AUSTENITIC STAINLESS STEEL ALLOY WITH IMPROVED HIGH \\ TEMPERATURE STRENGTH AND CREEP-RESISTANCE
}

\author{
CRADA NO. ORNL98-0529 \\ Between \\ Oak Ridge National Laboratory \\ and \\ Special Metals Corporation-Huntington Alloys* \\ *(formerly INCO Alloys International, Inc.)
}

\begin{abstract}
In February of 1999, a Cooperative Research and Development Agreement (CRADA) was undertaken between Oak Ridge National Laboratory (ORNL) and Special Metals Corporation - Huntington Alloys (formerly INCO Alloys International, Inc.) to develop a modified wrought austenitic stainless alloy with considerably more strength and corrosion resistance than alloy $800 \mathrm{H}$ or $800 \mathrm{HT}$, but with otherwise similar engineering and application characteristics. Alloy $800 \mathrm{H}$ and related alloys have extensive use in coal flue gas environments, as well as for tubing or structural components in chemical and petrochemical applications. The main concept of the project was make small, deliberate elemental microalloying additions to this Fe-based alloy to produce, with proper processing, fine stable carbide dispersions for enhanced high temperature creep-strength and rupture resistance, with similar or better oxidation/corrosion resistance.

The project began with alloy 803 , a Fe-25Cr-35NiTi,Nb alloy recently developed by INCO, as the base alloy for modification. Smaller commercial developmental alloy heats were produced by Special Metals. At the end of the project, three rounds of alloy development had produced a modified 803 alloy with significantly better creep resistance above $815 \mathrm{EC}(1500 \mathrm{EC})$ than standard alloy 803 in the solution-annealed (SA) condition. The new upgraded 803 alloy also had the potential for a processing boost in that creep resistance for certain kinds of manufactured components that was not found in the standard alloy. The upgraded 803 alloy showed similar or slightly better oxidation and corrosion resistance relative to standard 803. Creep strength and oxidation/corrosion resistance of the upgraded 803 alloy were significantly better than found in alloy $800 \mathrm{H}$, as originally intended. The CRADA was terminated in February 2003. A contributing factor was Special Metals Corporation being in Chapter 11 Bankruptcy. Additional testing, further commercial scale-up, and any potential invention disclosures were not pursued.
\end{abstract}




\section{Objectives}

One objective of this project was to improve the high temperature creep resistance of the recently developed 803 alloy, while another was to have a wrought modified 803 alloy with significantly better creep resistance and corrosion resistance than the commonly used alloy $800 \mathrm{H}$. The project was intended to use the established expertise at ORNL to design specific microalloying element additions to appropriately tailor the microstructure during aging or creep so that fine, stable carbides develop for strength. If possible, oxidation/corrosion resistance at high temperatures would also be enhanced. Optimum processing was to be developed for plate and tube products.

\section{Benefits to DOE Mission}

This program directly benefits DOE Fossil Energy programs by providing a costeffective advanced boiler material that can withstand fireside and steam side corrosion with higher temperature capability, which enables higher efficiency and reduces greenhouse gas emissions. This program also benefits DOE in general, because alloy 803 is also used in advanced chemical and petrochemical processing equipment at high temperatures. The benefit to a major U.S. specialty materials company is improved technology that should contribute to improving the economy.

\section{Technical Discussion of Work Performed}

The work performed on this CRADA was organized into several rounds of modified alloy production, followed by screening tests to evaluate performance. Screening tests included tensile testing at room temperature and 650, 760, and $870 \mathrm{EC}$ (1200, 1400 and 1600EF), and creep testing at 815EC (1500EF) at up to $70 \mathrm{MPa}(10 \mathrm{ksi})$. Screening also involved combinations of oxidation, sulfidation and carburization testing relevant to potential applications. The final portion of the project was to evaluate microstructural behavior and properties changes to determine the one or two candidate alloys for further scale-up and more detailed testing.

\section{1st Round of Modified 803 Alloy Development}

Standard alloy 803 , which contains $25 \mathrm{Cr}$ and $35 \mathrm{Ni}$, and a combination of $\mathrm{Ti}$ and $\mathrm{Nb}$, and six new modified 803 alloys were made, rolled to intermediate thickness hot-band at Special Metals, and then given final hot-rolling and solution annealing (SA) processing steps at ORNL. Alloys were designated 1A-1F, with 1 signifying the first round of alloys, and the second letter indicating the alloys within that round. Alloys $1 \mathrm{~B}$ and $1 \mathrm{C}$ were found to have the best relative creep resistance and target microstructural behavior (austenite plus minimal MC carbides, with no $\mathrm{Cr}$-rich $\mathrm{M}_{23} \mathrm{C}_{6}$ carbides in the as-processed condition). These 
modified alloys were weaker in tensile strength, had slightly less resistance to oxidation and corrosion, and were similar in creep resistance to the standard 803 alloy at $815 \mathrm{EC}(1500 \mathrm{EF})$, but with higher rupture ductility. The $1 \mathrm{~B}$ and $1 \mathrm{C}$ modified 803 alloys also showed a significant increase in creep resistance with modified processing that was not found at all in standard 803 (Fig. 1). Both 1B and $1 \mathrm{C}$ alloys also met the microstructural targets (Fig. 2), so they were chosen as the basis for further microalloying to enhance performance.

\section{2nd and 3rd Round of Modified 803 Alloy Development}

Three new modified 803 alloys were made, with $2 \mathrm{~A}$ and $2 \mathrm{~B}$ being modifications of $1 B$, and $2 \mathrm{C}$ being a modification of $1 \mathrm{C}$. These alloys had slightly better tensile strength at elevated temperatures (650 - 870EC or 1200-1600EF) than the 1st round alloys ( $1 \mathrm{~B}$ and $1 \mathrm{C}$ ), and were close to the base alloy, all with good ductility. The 2A had much better creep resistance in the SA condition (about 4 times better) compared to standard 803 alloy, and a large increase in creep resistance with modified processing (12 times better), similar to that found in the $1 \mathrm{C}$ alloy (Fig. 1). Alloy $2 \mathrm{~A}$ was better in creep than 2B, and slightly better than $2 \mathrm{C}$.

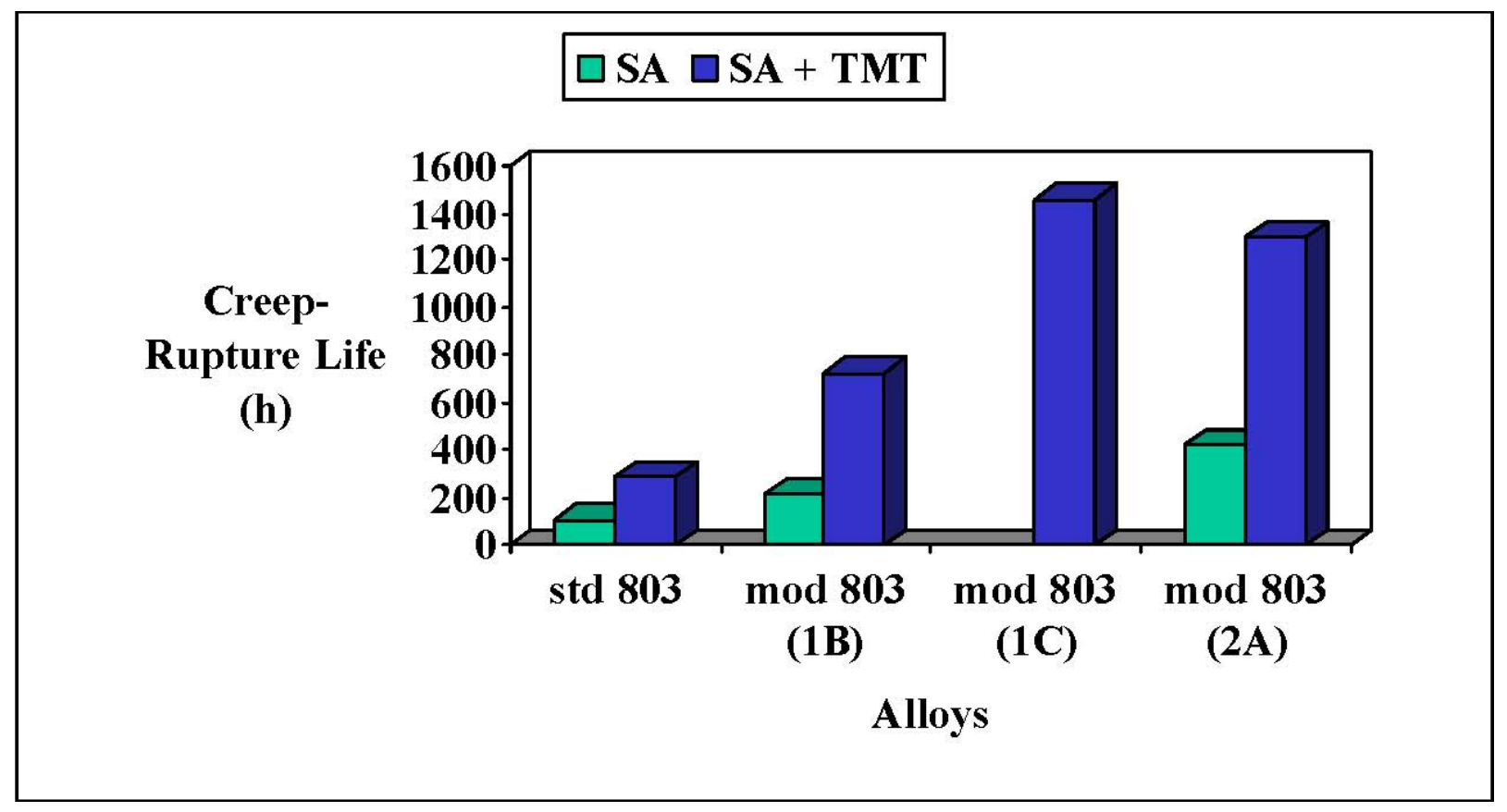

Fig. 1-Results of creep rupture tests at ORNL of the various alloys indicated at 815EC (1500EF) and $70 \mathrm{MPa}(10 \mathrm{ksi})$ in air. 
Oxidation and carburization resistance of the $2 \mathrm{~A}-2 \mathrm{C}$ alloys was similar to the standard 803 alloy. However, sulfidation testing at 815EC (1500EF) showed a clear benefit of $2 \mathrm{~A}$ relative to the other alloys. Therefore, $2 \mathrm{~A}$ appeared to be the best overall alloy from the 2 nd round alloys.

A third round of alloys to improve both the creep and the oxidation/corrosion resistance relative to the 2 nd round alloys was made, with $3 A-3 C$ alloys being modifications of a compromise between the $2 \mathrm{~A}$ and $2 \mathrm{C}$ alloys. Tensile strengths of the 3 rd round alloys were similar to those of the 2 nd round, while the relative creep resistance at 815EC (1500EF) was poorer, in both the SA and modified processing conditions. The oxidation and carburization resistances of all three 3rd round alloys were similar to the standard 803 alloy, and had the same good sulfidation resistance as shown by alloy 2A (Fig. 3).

It was concluded that the best upgrade 803 alloy was the $2 \mathrm{~A}$ alloy, and that alloy was selected for additional consideration for further scale-up.

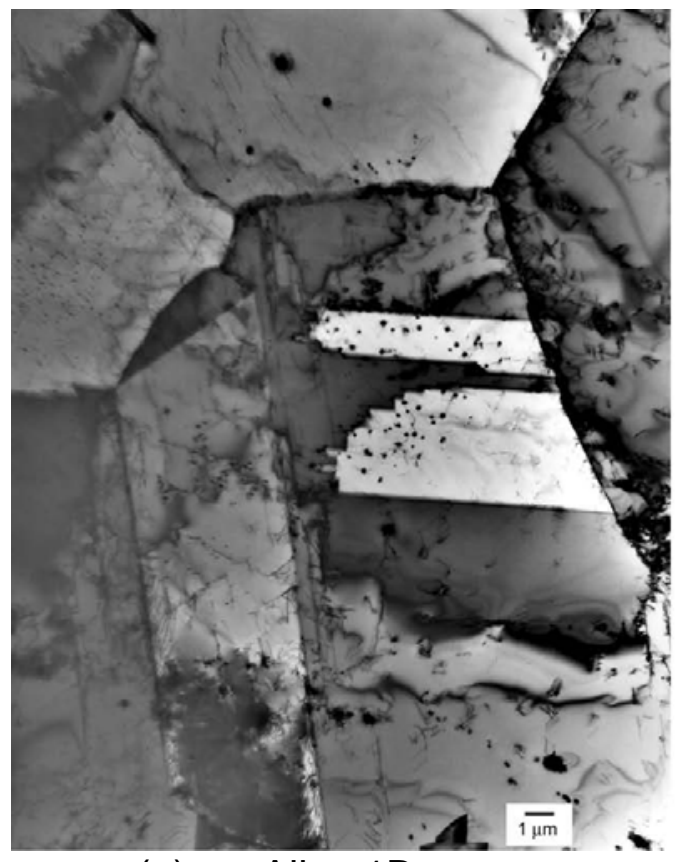

(a) Alloy 1B

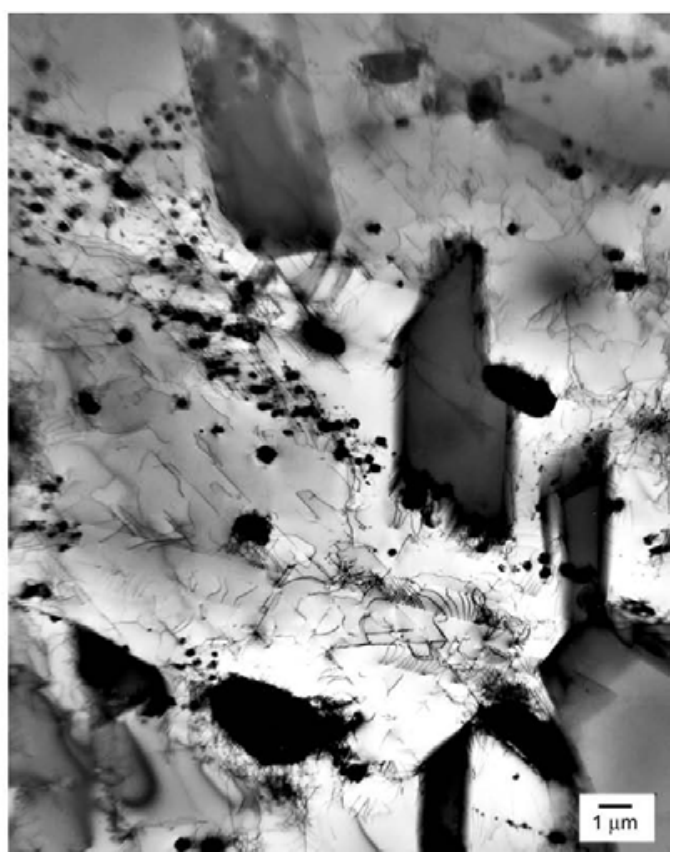

(b) Alloy $1 \mathrm{E}$

Fig. 2 - TEM micrographs of modified 803 alloys in as-hot-rolled and solution annealed condition, for (a) alloy $1 \mathrm{~B}$ and (b) alloy 1E. Alloy 1B has only a small amount of $\mathrm{MC}$ carbides in the austenite matrix, whereas alloy $1 \mathrm{E}$ has coarser dispersions of $\mathrm{MC}$ and $\mathrm{M} 23 \mathrm{C} 6$ carbides.

\section{Inventions}

No invention disclosures were filed on this CRADA due to the early termination of the project. However, the best candidates for alloy compositions sufficiently 
different than the standard 803 alloy were the 3rd round alloys, which did not show superior overall properties behavior. The 2 nd round alloys were judged not to have sufficiently different compositional differences from the standard 803 alloy range to warrant an invention disclosure.

\section{Commercialization Possibilities}

The modified $8032 \mathrm{~A}$ alloy has potential as an improved and upgraded version of the standard alloy for tubing applications, including boiler tubing and chemical/petrochemical ethylene furnace tubing applications. Preliminary testing data on foils also suggests potential for compact heat exchangers used in microturbine recuperator or fuel cell fuel reformer applications. There may also be applications replacing alloy $800 \mathrm{H}$ and $800 \mathrm{HT}$ for thin section bellows and flexible connections applications.

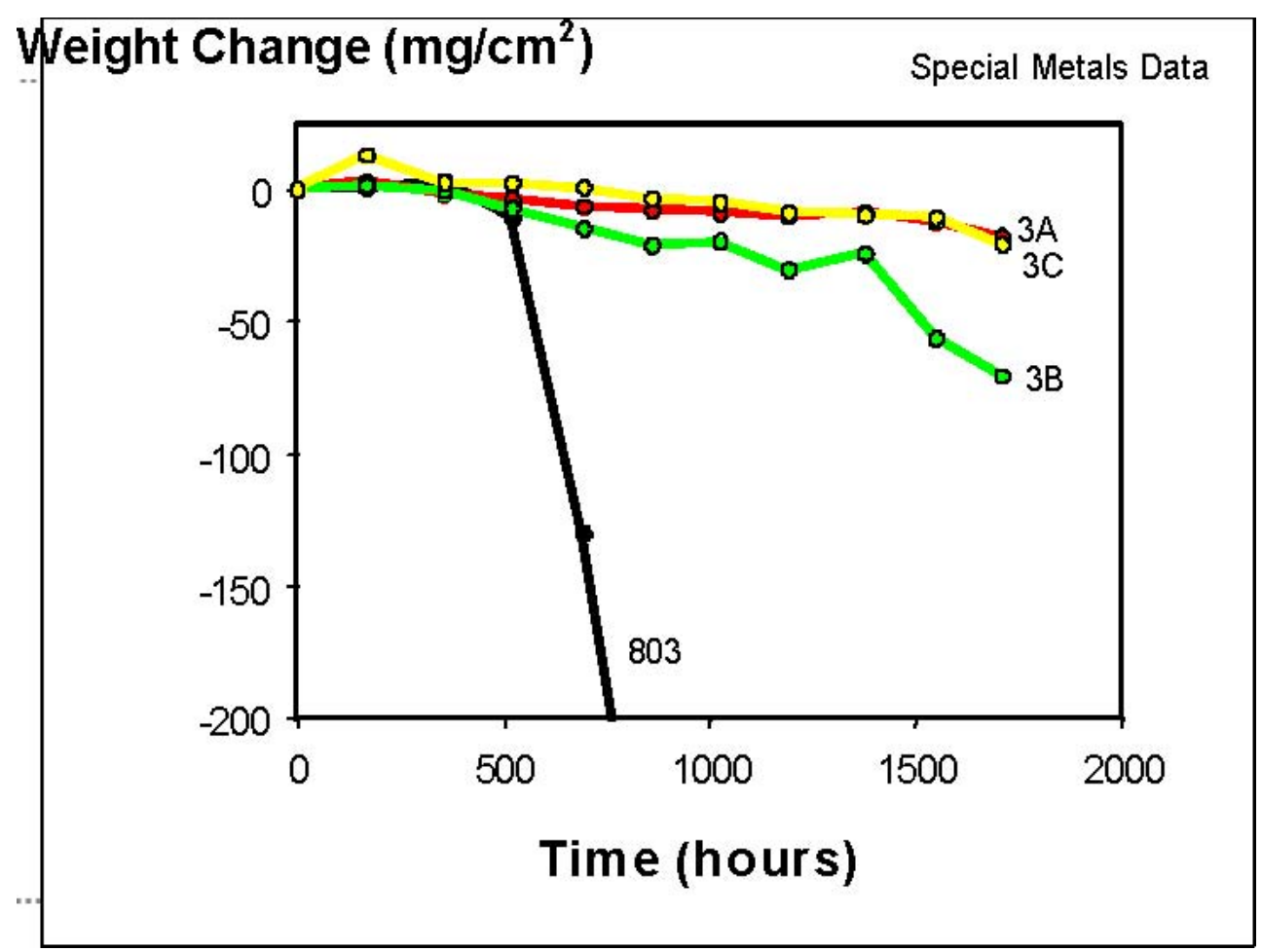

Figure 3-Sulfidation testing at Special Metals of 3rd round modified 803 alloys and standard alloy at 815EC (1500EF). 


\section{Plans for Future Collaboration}

While several application possibilities and preliminary alloy scale of plans have been generally discussed, there are no formal plans for future collaboration or follow-up at this time due to Special Metals Corporation being in Chapter 11 Bankruptcy at the time.

\section{Conclusions}

An upgraded version of alloy 803 has been developed after several rounds of alloy development, based on high temperature tensile, creep-rupture and corrosion testing. The upgraded version shows similar tensile properties and improved creep rupture resistance at 815EC (1500EF) in the SA condition relative to standard alloy 803 . Modified processing relevant to plate and tube products further improves the creep resistance of the upgrade 803 alloy, while such behavior is not found for standard alloy 803 . The upgraded alloy also has similar oxidation/corrosion resistance and better sulfidation resistance than the standard alloy. The next step in this alloy development effort is commercial scale-up. 


\title{
DISTRIBUTION
}

\author{
Internal Distribution
}

1. E. E. Bloom, 4500S, MS-6132

2. P. A. Carpenter, $4500 \mathrm{~N}, \mathrm{MS}-6269$

3. E. Lara-Curzio, 4515, MS-6069

4. P. J. Hadley, 4500S, MS-6161

5. R. R. Judkins, 4508, MS-6084

6. C. T. Liu, $4500 \mathrm{~S}, \mathrm{MS}-6115$

7. P. J. Maziasz, $4500 \mathrm{~S}, \mathrm{MS}-6115$

8. Office of Technical Information \& Classification, 6011, MS-6283

9. T. M. Rosseel, 4500S, MS-6161

10. R. W. Swindeman, 4500S, MS-6155

11. K. M. Wilson, $4500 \mathrm{~N}, \mathrm{MS}-6196$

12. I. G. Wright, 4500 S, MS-6156

13. DOE-WFO, 1000, MS-6269

\section{External Distribution}

14. F. M. Glaser, Physical Scientist, Office of Advanced Research, FE25/Germantown Building, U.S. Department of Energy, 1000 Independence Ave., S.W., Washington, D.C. 20585-1290

15. U. S. Rao, Physical Scientist, Gasification and Combustion Projects, U.S. Department of Energy, National Energy Technology Laboratory (NETLPGH), P. O. Box 10940, 626 Cochrans Mill Road, Pittsburgh, PA 15236.

16. R. B. Read, General Engineer, Gasification and Combustion Projects, U.S. Department of Energy, National Energy Technology Laboratory (NETL-PGH), P. O. Box 10940, 626 Cochrans Mill Road, Pittsburgh, PA 15236

17. R. R. Romanosky, Jr., Product Manager, Power Systems Advanced Research, U.S. Department of Energy, National Energy Technology Laboratory, (NETL-MGN), P. O. Box 880, 3610 Collins Ferry Road, Morgantown, WV 26507-0880

18. G. D. Smith, Special Metals Corporation, Special Metals Corporation Huntington Alloys, 3200 Riverside Drive, Huntington, WV 25705

19. DOE-WFO, 1000, MS-6269 